\title{
A constituição do Curso de Licenciatura em Ciências da Natureza: Química e Biologia do Instituto Federal de Ciência e Tecnologia - Campus Porto Alegre
}

The constitution of the Degree Course in Nature Sciences: Chemistry and Biology of the Federal

Institute of Science and Technology - Campus Porto Alegre

La constitución del Grado en Ciencias de la Naturaleza: Química y Biología del Instituto Federal de Ciencia y Tecnología - Campus Porto Alegre

Recebido: 16/05/2021 | Revisado: 21/05/2021 | Aceito: 29/06/2021 | Publicado: 12/07/2021

\author{
Fernanda Ponticelli Zabiela \\ ORCID: https://orcid.org/0000-0001-6033-8183 \\ Universidade Federal do Rio Grande do Sul, Brasil \\ Andréia Modrzejewski Zucolotto \\ ORCID: https://orcid.org/0000-0002-4889-5945 \\ Instituto Federal de Ciência e Tecnologia do Rio Grande do Sul, Brasil \\ E-mail: andreia.zucolotto@poa.ifrs.edu.br
}

\begin{abstract}
Resumo
São apresentadas as concepções dos professores enquanto organizadores de um curso de formação de professores com caráter inovador, o Curso de Licenciatura em Ciências da Natureza: Química e Biologia, oferecido pelo Instituto Federal de Ciência e Tecnologia - Campus Porto Alegre, em resposta à demanda nacional de professores na área de Ciências da Natureza. Para a construção do corpus de análise foram utilizadas as transcrições das entrevistas realizadas com professores idealizadores e elaboradores do curso, tendo na Análise Textual Discursiva a metodologia de análise. Ainda, no referido artigo, é possível conhecer a estrutura curricular do curso por meio da análise de excertos do Projeto Político Pedagógico do Curso. Por meio da análise das entrevistas foi possível conhecer as etapas que culminaram com a construção do curso, seus percalços e acertos, além de permitir conhecer a persistência e dedicação dos professores em criar um curso com uma identidade única, capaz de formar egressos preparados para suprir a carências por professores empenhados na profissão professor.
\end{abstract}

Palavras-chave: Ensino; Formação de professores; Interdisciplinaridade.

\begin{abstract}
Teachers' conceptions are presented as organizers of an innovative teacher training course, the Degree Course in Natural Sciences: Chemistry and Biology, offered by the Federal Institute of Science and Technology - Campus Porto Alegre, in response to national demand of teachers in the area of Natural Sciences. For the construction of the analysis corpus, the transcripts of the interviews carried out with teachers who created and developed the course were used, using the Discursive Text Analysis as the analysis methodology. Still, in the referred article, it is possible to know the course's curricular structure through the analysis of excerpts from the Political Pedagogical Project of the Course. Through the analysis of the interviews it was possible to know the stages that culminated with the construction of the course, its mishaps and successes, in addition to allowing to know the persistence and dedication of the teachers in creating a course with a unique identity, capable of forming graduates prepared to supply to shortages by teachers engaged in the teaching profession.
\end{abstract}

Keywords: Teaching; Teacher training; Interdisciplinarity.

\section{Resumen}

Las concepciones de los docentes se presentan como organizadores de un innovador curso de formación docente, el Curso de Licenciatura en Ciencias Naturales: Química y Biología, ofrecido por el Instituto Federal de Ciencia y Tecnología - Campus Porto Alegre, en respuesta a la demanda nacional de docentes en el área de Ciencias Naturales. Para la construcción del corpus de análisis se utilizaron las transcripciones de las entrevistas realizadas a los docentes que crearon y desarrollaron el curso, utilizando el Análisis Discursivo de Texto como metodología de análisis. Aún así, en ese artículo es posible conocer la estructura curricular del curso a través del análisis de extractos del Proyecto Político Pedagógico del Curso. A través del análisis de las entrevistas, se pudo conocer las etapas que culminaron con la construcción del curso, sus percances y aciertos, además de permitir conocer la perseverancia y dedicación de los docentes en crear un curso con una identidad única, capaz de formar egresados preparados para suplir la escasez de docentes que ejercen la profesión docente.

Palabras clave: Ensenãnza; Formación docente; Interdisciplinariedad. 


\section{Introdução}

A formação e qualificação dos profissionais da educação básica tornou-se foco de debates entre pesquisadores (Gatti, 2014; Nóvoa, 1995; Sacristán, 1999) a partir da importância recebida pela educação básica no decorrer do século 20. "As reformulações propostas na estrutura e nos objetivos da educação básica têm consequências importantes sobre a necessidade de repensar a formação inicial de professores" (Passos \& Santos, 2020, p.3) Esses diálogos em torno da formação docente são referências para as investigações educativas e fundamentais para os processos de reforma dos sistemas educativos, uma vez que pesquisas e reformas andam juntas, mesmo que nem sempre em sintonia perfeita, conforme os jogos de poder que se equacionam na promulgação das mesmas.

Assim, com a implementação de diferentes reformas educacionais, os cursos de formação de professores precisaram se adequar às necessidades preconizadas pela nova Lei de Diretrizes e Bases da Educação Nacional - LDB (Brasil, 1996), a qual formulou a necessidade de capacitação de todos os professores em exercício em nível superior até o ano de 2010. Ainda, o Plano Nacional de Educação (Brasil, 2001a, 2010) deixou evidente a importância de um incremento nas instituições de ensino superior com oferta de cursos de Licenciatura (Brasil, 2001a).

Durante esse processo de criação de instituições de ensino superior foram criados os Institutos Federais de Educação, Ciência e Tecnologia (IFs) constituídos pela Lei 11.892 de 29 de dezembro de 2008 (Brasil, 2008). Ficou determinado pela referida lei que essas instituições deveriam utilizar $20 \%$ de suas vagas para oferta de cursos superiores de licenciatura, para a formação de professores para atuarem na educação básica, com formação preferencialmente nas áreas de ciências e matemática.

Assim como ficou definido na LDB, os cursos de formação de professores precisavam sofrer modificações significativas, de modo a atender às necessidades educacionais vigentes. Com a aprovação das Diretrizes Curriculares Nacionais para a Formação de Professores da Educação Básica (Brasil, 2001b), a profissão professor passou a ser entendida como uma carreira que tem suas especificidades e que necessita de uma atenção exclusiva. Essa definição está em consonância com alguns autores que já preconizavam tal entendimento, especialmente Nóvoa (1995), que defende a profissionalização docente. Com isso, não seria mais aceita a formação de professores baseados no antigo esquema " $3+1$ ", em que a formação pedagógica tinha um caráter de complementação da formação do bacharel.

As Diretrizes para Formação de Professores lançadas em 2015 (Brasil, 2015a) e, a mais atual lançada em 2019 (Brasil, 2019), que está em consonância com a Base Nacional Curricular Comum para a educação básica, preconizavam a importância da organização curricular orientada pelo perfil profissional esperado. Compreende-se que a formação de professores deve ser pautada pelo desenvolvimento de competências que propiciem aos professores a possibilidade de desenvolver um trabalho interdisciplinar, através de eixos articuladores, que possibilitam a compreensão integradora das ciências.

Nesse contexto de desenvolvimento de novos cursos de formação de professores, o Instituto Federal, Campus Porto Alegre, implantou um curso de caráter inovador, que tem por objetivo formar professores para atuarem na educação básica, através de um currículo que preconiza a articulação entre saberes científicos e pedagógicos. Com isso, essa pesquisa tem por objetivo investigar como o Instituto Federal de Ciência e Tecnologia - Campus Porto Alegre, propôs o Curso de Licenciatura em Ciências da Natureza: Química e Biologia, por meio de entrevistas com os professores organizadores do curso.

\section{Curso de Licenciatura em Ciências da Natureza: Química e Biologia}

Apesar de o ensino de ciências, nas escolas e na formação de professores, continuarem sendo marcados pela fragmentação e pela linearidade de conteúdo, existe uma necessidade atual de integrar disciplinas e de contextualizar os conteúdos de ensino de forma mais significativa. Para Santomé (1998, p.45) "o mundo atual precisa de pessoas com uma formação cada vez mais polivalente para enfrentar uma sociedade na qual a palavra mudança é um dos vocabulários mais 
frequentes".

Desse modo, emerge a importância de ter um novo olhar nos cursos de formação de professores de ciências. Os novos cursos possibilitariam espaços para a reflexão, através de uma prática dialógica e coletiva entre as diferentes disciplinas, buscando desenvolver futuros profissionais para a educação básica, com foco nas áreas de conhecimento e não mais na formação disciplinar fragmentada tradicional. Desse modo, desenvolve-se dentro do curso uma estrutura de cooperação entre os especialistas (Japiassu, 1976), promovendo o desenvolvimento de competências que poderão proporcionar aos egressos estarem preparados para atuarem de modo interdisciplinar, que possuam perfil para atuar em áreas mais amplas do conhecimento e não apenas numa disciplina específica.

Diante de tais exigências, se fez necessário repensar os cursos de licenciatura e abandonar a formação compartimentada e disciplinar, adotando uma nova prática, dialógica e interdisciplinar, assim como afirma Santomé (1998) ao discorrer que para uma prática interdisciplinar é necessário a comunhão de diferentes ideias. Os futuros professores passariam a conhecer os diferentes pontos de vistas de outros especialistas e de seus pares, o que possibilitaria a construção de um conhecimento mais amplo e integrado das ciências. Como reflexo dessas considerações, e no contexto da legislação de construção dos Institutos Federais, nasce o curso de Licenciatura em Ciências da Natureza: Biologia e Química do Instituto Federal de Ciência e Tecnologia do Rio Grande do Sul - Campus Porto Alegre (IFRS - Campus POA).

Cabe referir que o IFRS - Campus POA, nasceu a partir da desvinculação da Escola Técnica da Universidade do Rio Grande do Sul, e incorporação da mesma pelos Institutos Federais, diante da publicação da Lei 11.892, em 29 de dezembro de 2008, em que foram criados 38 Institutos Federais no País. A referida lei enfatiza a necessidade de formação de professores nas áreas de ciências e matemática, uma vez que estes eixos de conhecimento representam o maior déficit de profissionais capacitados. Com isso, diante das necessidades preconizadas pelo MEC, IFRS - Campus POA, optou por ofertar o curso de Licenciatura em Ciências da Natureza: Biologia e Química.

O Projeto Pedagógico da licenciatura estudada, assume como objetivo construir um curso para atender às demandas atuais da educação brasileira de formação de professores, preparados para integrar uma sociedade cada vez mais moderna e que demandava o conhecimento de diferentes tecnologias. Com isso, os professores idealizados do curso, buscaram formar professores que estivessem em sintonia com os preceitos da LDB de 1996 e das DCN de Formação de Professores, e comprometidos com a aprendizagem do aluno, bem como ativos no processo administrativo da escola.

O curso foi estruturado em nove etapas, ou seja, nove semestres, totalizando quatro anos e meio de duração. Cada etapa possuía um Tema Estruturante, relacionado as dimensões das Ciências da Natureza, do macro ao micro, a ser desenvolvido naquele semestre, dando origem assim ao nome do semestre. Cada etapa foi formada por três unidades de aprendizagem, denominadas Unidade de Aprendizagem Científica (UAC), Unidade de Aprendizagem Pedagógica (UAP) e Unidade de Aprendizagem Integradora (UAI), conforme a Tabela 1.

Nas Unidades de Aprendizagem são desenvolvidas as competências do futuro professor, cada Unidade de Aprendizagem possui um objetivo específico, mas orientadas por diferentes saberes, sejam eles, os saberes científicos (UAC) e os saberes pedagógicos (UAP), que são interligados nas UAIs, através de Projetos Integrados e nos estágios supervisionados.

O esquema Geral das UAs está apresentado no Quadro 1, na qual é possível observar a igualdade de importâncias das UAs, tendo na UAI atribuição de permitir ao aluno experimentar aquilo que ele irá ensinar enquanto professor, possibilitando momentos de reflexão coletiva sobre a prática pedagógica, sejam elas nos Projetos Integradores ou nos Estágios Supervisionados. 
Research, Society and Development, v. 10, n. 8, e29310816151, 2021

(CC BY 4.0) | ISSN 2525-3409 | DOI: http://dx.doi.org/10.33448/rsd-v10i8.16151

Quadro 1: Estrutura dos cursos.

\begin{tabular}{|c|c|c|c|c|}
\hline Etapa & Tema Estruturante & Unidade de Aprendizagem & Créditos & Total de créditos da Etapa \\
\hline \multirow{3}{*}{ I } & \multirow{3}{*}{ Terra e Universo } & Cientifica & 15 & \multirow{3}{*}{25} \\
\hline & & Pedagógica & 4 & \\
\hline & & Integradora & 6 & \\
\hline \multirow{3}{*}{ II } & \multirow[t]{3}{*}{ Matéria e suas transformaçōes } & Cientifica & 16 & \multirow{3}{*}{25} \\
\hline & & Pedagógica & 5 & \\
\hline & & Integradora & 4 & \\
\hline \multirow{3}{*}{ III } & \multirow{3}{*}{ Ambiente eEnergia } & Cientifica & 14 & \multirow{3}{*}{25} \\
\hline & & Pedagógica & 5 & \\
\hline & & Integradora & 6 & \\
\hline \multirow{3}{*}{ IV } & \multirow{3}{*}{ Vida e Energia } & Cientifica & 14 & \multirow{3}{*}{25} \\
\hline & & Pedagógica & 6 & \\
\hline & & Integradora & 5 & \\
\hline \multirow{4}{*}{ V } & \multirow{4}{*}{ Diversidade Biológica } & Científica & 12 & \multirow{4}{*}{29} \\
\hline & & Pedagógica & 5 & \\
\hline & & Integradora & $6+4^{4}$ & \\
\hline & & Optativa A & 2 & \\
\hline \multirow[t]{4}{*}{ VI } & \multirow[t]{4}{*}{ Vida e Ambiente } & Cientifica & 16 & \multirow[t]{4}{*}{28} \\
\hline & & Pedagógica & 2 & \\
\hline & & Integradora & $5+3^{4}$ & \\
\hline & & Optativa B & 2 & \\
\hline \multirow{4}{*}{ VII } & \multirow{4}{*}{ Vida e Evolução } & Cientifica & 12 & \multirow[t]{4}{*}{28} \\
\hline & & Pedagógica & 4 & \\
\hline & & Integradora & $5+3^{4}$ & \\
\hline & & Optativa C & 2 & \\
\hline \multirow{4}{*}{ VIII } & \multirow{4}{*}{ Saúde e Tecnologia } & Cientifica & 14 & \multirow[t]{4}{*}{28} \\
\hline & & Pedagógica & 4 & \\
\hline & & Integradora & $5+3^{4}$ & \\
\hline & & Optativa E & 2 & \\
\hline \multirow{4}{*}{ IX } & \multirow{4}{*}{ Ciência e Sociedade } & Cientifica & 10 & \multirow[t]{4}{*}{23} \\
\hline & & Pedagógica & 4 & \\
\hline & & Integradora & $4+3 * 4$ & \\
\hline & & Optativa F & 2 & \\
\hline
\end{tabular}

Fonte: PPC Curso. ${ }^{1}$

${ }^{1}$ Tal organização foi apresentada na primeira versão do Projeto Político Pedagógico do curso, sofrendo alterações nas revisões posteriores. A versão vigente pode ser encontrada no endereço: (http://www.poa.ifrs.edu.br/images/Cursos/Superiores/Licenciatura_Ciencias_Natureza_Biologia_Quimica/ppc-ciencias-danatureza-vigencia2017-2.pdf).

No atual Projeto Político Pedagógico, as temáticas são: 
Figura 1: Esquema geral sobre a organização das etapas do Curso.

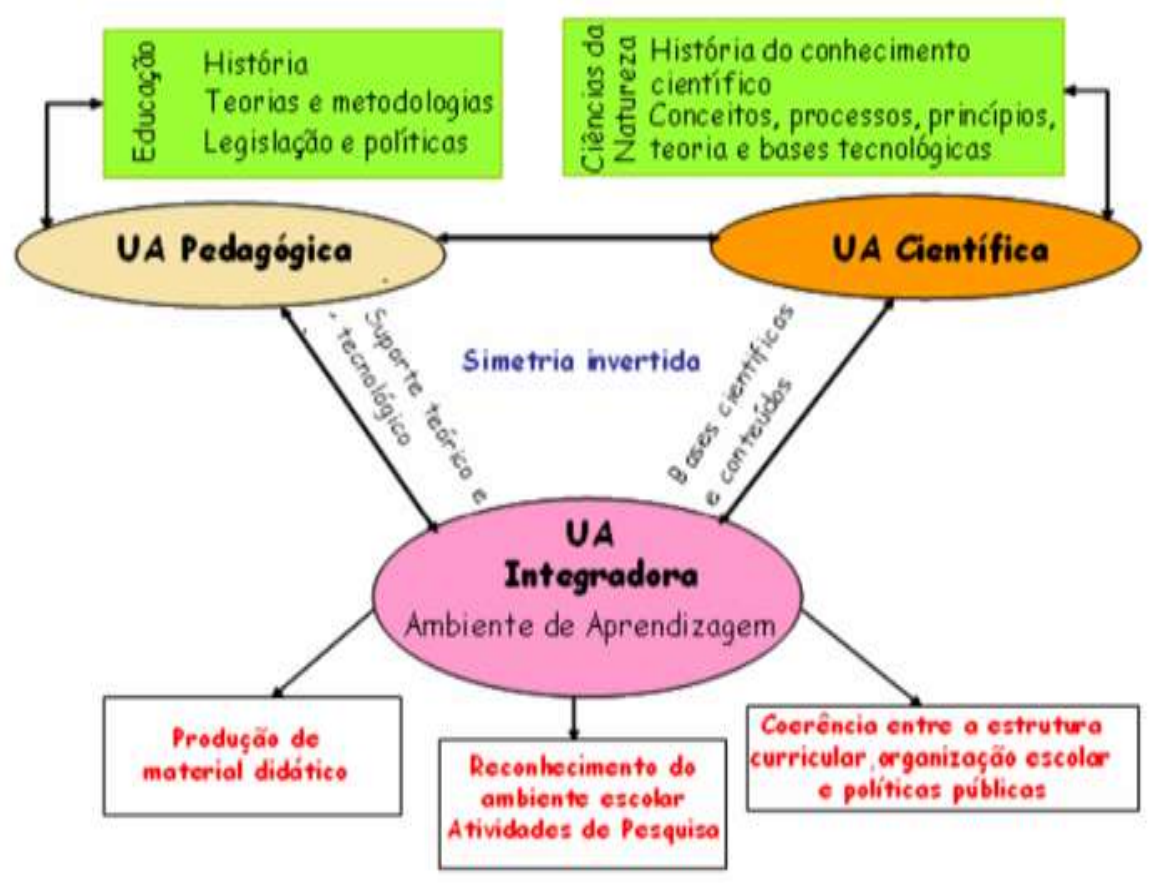

Fonte: PPC do Curso (versão 2010)

\section{Metodologia}

$\mathrm{Na}$ investigação sobre as concepções dos organizadores do Curso de Licenciatura em Ciências da Natureza: Química e Biologia, foram utilizadas entrevistas semiestruturadas como instrumento de coleta de dados. A entrevista na pesquisa qualitativa privilegia a fala dos entrevistados, permitindo atingir um alto nível de compreensão do objeto de estudo. Para Gil (1999, p.117) "é a técnica em que o investigador se apresenta frente ao investigado e lhe formula perguntas, com o objetivo de obtenção dos dados que lhe interessam a investigação". Desse modo, a entrevista semiestruturada mostrou-se como melhor técnica para ter acesso às informações sobre opinião, concepções, expectativas e percepções dos organizadores do curso, por não apresentar perguntas fechadas e suscitar respostas não rígidas.

Para a realização das entrevistas utilizou-se uma entrevista semiestruturada como instrumento de coleta das informações, de modo a garantir que a mesma pergunta fosse feita da mesma forma para todos os entrevistados. Gil (2014, p.121) explica que "a entrevista [...] desenvolve-se a partir de uma relação fixa de perguntas, cuja ordem e redação permanece invariável para todos os entrevistados, que geralmente são em grande número". Nessa técnica de pesquisa, apesar do entrevistado poder falar livremente sobre o assunto, o pesquisador deverá guiar a entrevista, retomando ao tema original caso o entrevistado desvie do assunto, tal como se sucedeu nessa investigação.

Para a construção do corpus de análise foram transcritas as onze entrevistas realizadas com professores, dentre os dezessete responsáveis pela organização do curso. As entrevistas foram realizadas presencialmente na própria instituição, com duração variável, e foram gravadas utilizando um aplicativo de celular. A cada professor participante da pesquisa foram esclarecidos os objetivos, as implicações de sua participação e o caráter voluntário e confidencial da mesma. Após concordarem, foi solicitada a assinatura do Termo de Consentimento Livre e Esclarecido (TCLE).

"As etapas, por sua vez, estão articuladas por meio de temas estruturantes que se relacionam com diferentes dimensões do Ensino de Ciências da Natureza, conforme segue: I. Terra e sua composição (etapas I e II) II. Terra e suas transformações (etapas III e IV) III. Vida e sua organização (etapas V e VI) IV. Vida e Evolução (etapa VII) V. Vida e Sociedade (etapas VIII e IX) As etapas são formadas por três unidades de aprendizagem, denominadas Unidade de Aprendizagem das Ciências da Natureza (UACN), Unidade de Aprendizagem Pedagógica (UAP) e Unidade de Aprendizagem Integradora (UAI)." 
As entrevistas foram transcritas em texto corrente, e posteriormente submetidas à Análise Textual Discursiva (Moraes \& Galiazzi, 2011), cujas etapas estão definidas na Figura 2:

Figura 2: Sequência da Análise Textual Discursiva.

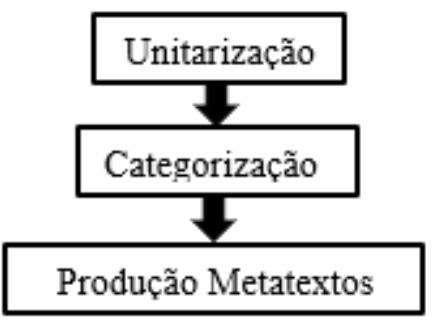

Fonte: Autores.

Na unitarização são definidas as unidades de sentido através da desconstrução das entrevistas, são organizadas em conjuntos as frases que possuem o mesmo sentido. A partir da leitura das frases organizadas, surgem as primeiras categorias, por meio de um processo indutivo, comparando e organizando o conjunto de elementos semelhantes. O processo de categorização partiu de um conjunto de nove categorias mais específicas para então chegar nas subcategorias, compostas por um conjunto de três de categorias gerais, apresentadas no Quadro 2.

Quadro 2: Categorias e Subcategorias emergentes.

\begin{tabular}{|c|c|}
\hline Categorias Específicas & Categorias Gerais \\
\hline Início & \multirow{3}{*}{ O Começo de uma História } \\
\hline Objetivo & \\
\hline O Curso & \\
\hline Estrutura do Curso & \multirow{3}{*}{ A marca de uma identidade única } \\
\hline Inovação & \\
\hline Interdisciplinaridade & \\
\hline Obstáculos & \multirow{3}{*}{$\begin{array}{l}\text { Superando os obstáculos e escrevendo um novo } \\
\text { capítulo na educação }\end{array}$} \\
\hline Soluções & \\
\hline Assertivo & \\
\hline
\end{tabular}

Fonte: Autores.

Após a organização das subcategorias, iniciou-se a produção dos metatextos, baseado na interpretação das pesquisadoras sobre o tema, permeados pela fundamentação teórica que sustenta a pesquisa, que foram construídas pelas leituras sobre a formação superior no Brasil (Brasil, 2002, 2015, 2019), A Rede Federal de Educação Profissional, Científica e Tecnológica (Brasil, 2008, 2019) e a Interdisciplinaridade (Japiassu, 1976; Santomé, 1998; Fazenda, 2003, 2011, 2017). O propósito dessa última etapa é a de construir textos descritivos, ricos em argumentos produzidos pela pesquisadora através de “insights" produzidos pela imersão no corpus de análise permitindo, assim, a compreensão das experiências dos professores no processo de construção do curso.

Para garantir o sigilo compactuado por meio do Termo de Consentimento Livre e Esclarecido, os entrevistados serão 
identificados como "professor" e foram utilizadas as letras do alfabeto de A até K, e suas falas serão apresentadas em itálico quando um excerto é citado no texto.

\section{Resultados e Discussão}

Com base na imersão e análise das entrevistas, foi possível construir textos que expressaram a compreensão das pesquisadoras, sobre as experiências pessoais dos professores envolvidos na criação do curso ora estudado. A seguir, são apresentados os metatextos, que foram organizados como uma grande ceia, da pesquisa da receita à cereja do bolo. Apreciamos abaixo o envolvimento e a dedicação de cada professor envolvido na constituição do curso, passando por momentos de turbulências, que proporcionaram a busca incansável por alternativas viáveis para a realização do projeto, que permitiram assim, a colheita do fruto sonhado.

\section{O começo de uma história}

A proposta inicial de um curso superior surgiu de um grupo pequeno de professores que faziam parte da antiga Escola Técnica da Universidade Federal do Rio Grande do Sul (UFRGS), no contexto da proposta dos Instituto Federais de Ciência e Tecnologia encamparem as escolas técnicas, e da obrigatoriedade da destinação de vagas para formação de professores, prioritariamente para o ensino de ciência e matemática. Com isso, em dezembro de 2008, a Escola Técnica deixa de existir e nasce o então Campus Porto Alegre do Instituto Federal de Educação Ciência e Tecnologia do Rio Grande do Sul.

A ideia do curso surgiu com base em dois aspectos, segundo seus idealizadores. O primeiro era a carência de professores de Química, Biologia e de Ciências no município de Porto Alegre e na região metropolitana. O segundo era a intenção de aproveitar o quadro de professores que a escola técnica possuía com tradição nessa área. Como a escola técnica possuía o curso de Técnico em Biotecnologia e de Técnico em Química, pensaram em organizar dois cursos de Licenciatura, um de Biologia e outro de Química.

Inicialmente foi feito uma análise na oferta de cursos de Licenciatura nessas áreas, em atuação, em Porto Alegre e na região metropolitana. Constataram-se que já existiam uma quantidade grande de oferta de vagas, seja na rede pública ou privada, o que não justificaria a criação de mais um (ou dois tradicionais) curso nesse formato. Além desse fato, mesmo com uma futura admissão de novos professores, ainda seria pequeno o número de professores para constituir dois cursos com quatro anos de duração. Pensando nesse aspecto, os professores então decidiram por organizar um curso inovador, que tivesse a formação em ambas as áreas, ou seja, um Curso de Licenciatura em Ciências, com Habilitação em Biologia e em Química.

Em um segundo momento, ocorreram os concursos para a admissão de professores, de modo a suprir a necessidade de professores para atuar no referido curso. Os novos professores de Química e Biologia, ficaram responsáveis pela finalização do projeto do curso, bem como um plano de ação e um projeto pedagógico. A organização dos cursos iniciou no final do ano de 2009, e a proposta deveria estar pronta até janeiro de 2010, para que em agosto de 2010 o curso já tivesse sua primeira turma em funcionamento.

O Projeto Pedagógico do Curso, no que diz respeito aos princípios e à sua concepção estava pronto no início do ano de 2010, mas a organização de cada componente curricular ocorreu nos semestres anteriores ao início daquele componente curricular, até que todo o projeto do curso estivesse pronto. Tal estrutura propiciou discussões importantes, mas ao mesmo tempo difíceis, devido às diferentes concepções dos professores que estavam à frente da organização curricular. O curso teve seu início com o coordenador do processo de implantação do curso, mas o recheio dele foi organizado a partir de uma construção coletiva. Segundo o professor I, "Um dos diferenciais para a organização do curso foi o apoio da equipe diretiva do IFRS e o trabalho do Professor [...], um dos idealizadores do formato inovador do curso, com caráter interdisciplinar e com habilitação integrada". 
Segundo os professores entrevistados, o processo de construção do curso foi muito rico enquanto diálogo, com momentos de discussões de concepções de ensino e de aprendizagem, momentos de aprendizagens de trocas de saberes entre todos envolvidos. Tal processo está em compasso com os preceitos de Fazenda (2017) quando afirma que as mudanças em uma instituição começam com profundas alterações no processo de capacitação docente, em que se permite modificar as concepções sobre o ensino, permitindo-se estar aberto a novas formas de diálogo.

Apesar das diferentes concepções, os professores tinham claro que o objetivo do curso era de formação de um docente. $\mathrm{O}$ grupo organizador do curso, tanto o primeiro grupo de trabalho (constituídos apenas por professores da antiga escola técnica) como aquele integrado também pelos novos professores, eram muito abertos a discussões e a novas ideias, estavam todos imbuídos com o espírito desse novo curso. Assim, cabe retomar que havia um grupo inicial de professores que foram responsáveis pela organização inicial, e depois esse grupo foi ampliado com a entrada de professores novos recém concursados.

O corpo docente responsável pela organização do curso, tinha o objetivo de construir um curso com um diferencial, que trabalhasse além das questões conteudistas, que se preocupasse com as questões pedagógicas, políticas e práticas, pois a maioria dos cursos já existentes possuíam uma estrutura de curso muito semelhante aos de bacharelado, contando apenas com uma pequena parte voltada à formação pedagógica, mesmo que a legislação já fosse diferente ainda mantinham uma cultura tradicional à época.

Tal ideia surgiu de um contexto histórico frente à excessiva fragmentação, repensando as fronteiras entre as disciplinas, buscando um diálogo interdisciplinar, de modo a atender uma demanda social de um mundo em constante modificação. Pierson e Neves afirmar que "a demanda pela interdisciplinaridade não é meramente acadêmica ou um privilégio científico, mas acima de tudo, é uma demanda social." (2001, p.2). Ainda, segundo o professor B, "os problemas do mundo atual são complexos e necessitam de um olhar pluralizado". Com isso, ao organizar o curso, os professores buscaram compreender primeiramente o que era preciso para ser um professor, o necessário para formar a profissão professor. Pois segundo professor E:

A profissão professor é difícil, exige uma demanda grande de tempo e de dedicação. Para ser professor é necessário estar em constante formação, buscar sempre novos estudos de modo a estar cada vez mais qualificado. Ser professor não é transpor conteúdo, não basta ter domínio do conteúdo, é preciso saber ensinar aquele conteúdo, para que o aluno possa entender e saber onde será aplicado toda teoria estudada. Ser professor é estar trabalhando com pessoas, e estar trabalhando com as informações que o professor possui ao longo do tempo, de modo que os alunos possam se apropriar dessas informações e questionar as competências desenvolvidas.

Com isso, o curso surgiu diante de uma perspectiva de limitações dos cursos ditos tradicionais, de modo a atender às demandas por professores na área das Ciências da Natureza. Formando professores com uma base consolidada na área de formação na educação, assim como uma área bem consolidada em Química e Biologia. Segundo o professor B, o "curso tinha como objetivo a formação de professores, uma vez que nos cursos tradicionais a identidade docente era secundária, formavamse excelentes biólogos ou químicos, mas professores mal resolvidos".

Assim o IFRS propôs a construção de um curso de Curso de Licenciatura em Ciências, com Habilitação em Biologia e em Química, como uma proposta inovadora, formando professores capazes de atuarem tanto no campo da Biologia como na da Química, ou seja, com duas áreas de aprofundamento. Surgiu por parte dos professores, a intenção de criar um curso para formar professores para atuarem em mais de uma especialidade, ou seja, o curso tem por objetivo formar professores para atuar na educação básica, com formação sólida em três áreas: Ciências, Química e Biologia.

A intenção dos idealizadores era proporcionar aos egressos maiores chances no mercado de trabalho, sejam em concursos ou em escolas particulares, uma vez que eles poderiam ser professores de Biologia, Química no Ensino Médio e de 
Ciências no Ensino Fundamental. Além disso, segundo o professor F:

a formação em duas especializações permite aos egressos se identificarem mais para uma ou para outra, fato que foi observado no decorrer do curso, apesar de eles terem a possibilidade de atuarem em duas áreas do ensino médio e no ensino fundamental.

Ao longo das entrevistas, foi possível compreender que esse é um dos grandes diferenciais do curso, possibilitando aos egressos que eles transitem entre as respectivas áreas de formação, ocupando uma lacuna conhecida quanto à formação de professores para ciências no Ensino Fundamental séries finais, e Biologia, Química, no Ensino Médio.

\section{A marca de uma identidade única}

Os professores iniciaram a organização do curso através da construção da grade curricular, mas durante esse processo eles perceberam que não seria possível montar o curso através da grade, pois primeiro era preciso ter uma ideia consolidada do que se espera de um curso. Para isso, durante o ano de 2009, os professores fizeram um estudo aprofundado dos cursos que existiam no Brasil que tinham as características do curso que estavam organizando. Segundo o professor C, durante a organização do curso, "buscou-se referências de alguns cursos que já existiam, algumas ideias, o que fazer e o que não fazer", ou seja, a intenção era ofertar um curso com características próprias, diferentes dos cursos de Licenciatura que já existiam.

Foram encontrados quatro cursos ao total no Brasil, quais sejam: o curso de Ciências Exatas da Universidade de São Paulo, campus São Carlos, o curso de licenciatura em Ciências exatas da Univates, o curso de licenciatura em Ciências da Universidade de São Paulo Leste e o curso de Ciências da Universidade de Brasília. Os professores analisaram os currículos e as ementas das disciplinas dos quatro cursos, algumas ementas eles adaptaram e outras foram copiadas, pois estava em compasso com o que eles esperavam para o curso.

A experiência dos professores integrantes também contribuiu na organização do curso. Com a chegada de novos professores surgiram novas ideias, uma construção coletiva, baseadas na história profissional de cada professor, segundo o entrevistado D, "alguns professores eram mais técnicos, outros mais pedagógicos, alguns já haviam trabalhado em cargos políticos e possuíam experiências quanto as questões governamentais". Já o professor E afirma que:

o curso tinha professor, na sua maioria, biólogos, químicos e pedagogos. Os biólogos eram mais complexos e os químicos mais sistemáticos, e os pedagogos forma importantes para fazer a aproximação desses dois grupos. Em um primeiro momento as linguagens eram diferentes, mas a pedagogia auxiliou a aproximação dos integrantes do grupo.

Foram vários momentos para discussões nas inúmeras reuniões de elaboração do PPC, até chegar à proposta de curso desejado. Diferentes concepções balizaram a organização do curso, o que provocou algumas divergências entre os professores quanto à estrutura do curso, e para ajudar na resolução desse impasse, foram escutadas ideias de pessoas externas ao curso.

Os professores organizaram o curso apoiado em três pilares, o pilar pedagógico, o pilar da Química e o pilar da Biologia, formando um curso robusto quanto ao objetivo de formar professores de Ciências para o Ensino Fundamental, de Química e de Biologia para o Ensino Médio, com preparo e bagagem para o exercício da profissão.

Uma questão importante também, na organização do curso, estava relacionada com a estrutura do Enem (Exame Nacional do Ensino Médio) e dos próprios Parâmetros Curriculares Nacionais para o Ensino Médio (Brasil, 1998, 2000, 2002, 2006). O Enem está dividido em áreas de conhecimento assim como os PCNs: área das linguagens e suas tecnologias, matemática e suas tecnologias, ciências humanas e suas tecnologias e ciências da natureza e suas tecnologias. Para os professores, existia a possibilidade de a educação básica passar a apresentar essa estrutura, e dessa forma, o curso estaria preparando professores para esse novo formato de educação básica, o que se percebe hoje na consolidação da Base Nacional 
Comum Curricular (Brasil, 2018), organizando o ensino médio por áreas do conhecimento ainda que o novo documento traga concepções distintas daquelas que norteavam os documentos anteriores e as concepções do curso em questão.

Além disso, o Enem, em 2009, deixou de ser uma prova de avaliação do ensino médio e passou a ser utilizado como seleção para ingresso na educação superior. Desse modo, seria importante que o curso organizado apresentasse uma estrutura de divisão das disciplinas semelhante às do Enem, pois, segundo o professor K, "se o Enem avalia os alunos através de grandes áreas, e não por conhecimentos específicos, não teria sentido continuar formando professores por disciplina e não por grandes áreas".

Com isso, os professores buscaram organizar um currículo que abordasse as temáticas e os conceitos que perpassam as ciências da natureza, e que fossem essenciais para formar um professor de ciências, com liberdade e sensibilidade para buscar outros conhecimentos no decorrer de sua carreira de professor. Para o professor K foi "então a ideia de organizar um curso com essa estrutura por áreas, com integração de diferentes conteúdos de ciências, dando origem então ao nome do curso, Licenciatura em Ciências da Natureza".

O currículo do curso possui disciplinas integradoras, científicas e pedagógicas, que para os professores tinham o objetivo de unir os conhecimentos pedagógicos, químicos e biológicos. O curso não possui somente ligação entre a Biologia e a Química, mas também tem uma base sólida na pedagogia. As questões filosóficas e sociológicas são discutidas, de modo a formar um professor com visão política capaz de formar e atuar como cidadão. Para os professores, tal proposição tinha como objetivo a formação de um professor dialético, apto para o exercício da profissão professor, e preparado para aceitar os diferentes posicionamentos dos outros professores.

Os semestres foram organizados por temática, totalizando nove semestres. Cada semestre do curso tem seu nome, um assunto principal, um tema a ser desenvolvido. Segundo os professores, as disciplinas forneciam embasamento para alcançar o objetivo geral, e para que isso acontecesse, as disciplinas precisavam ser interligadas, todos trabalhando juntos, a parte pedagógica e parte científica. Para atender os objetivos do curso, existia uma demanda por um número grande de disciplinas para a formação pedagógica e outras para as disciplinas integradoras. Segundo o professor F, "tal demanda fez com que o curso não tivesse uma formação técnica, pensada pelos professores das áreas exatas, mas acabasse por ter a estrutura pensada originalmente".

A organização das disciplinas foi um momento importante da estrutura do curso, em que os professores se dividiram para configurar as disciplinas. Os professores tinham em mente o perfil de egresso que o curso pretendia formar e com isso fizeram a organização curricular, tal como preconiza Fazenda (2011), ao afirmar que se deve inicialmente pensar nas necessidades do aluno e somente após elaborar o programa da disciplina. O curso foi dividido em unidades de aprendizagem, era preciso então definir o que seriam as unidades científicas, pedagógicas e integradoras, bem como suas ementas. Estava previsto que desde o início do curso os alunos teriam disciplinas pedagógicas e integradoras, momentos nos quais poderiam discutir o perfil de um professor, o que seria necessário para mudar a sociedade, as características de um professor diferente. Segundo o professor $\mathrm{H}$, "a disciplina integradora tinha então o objetivo de unir todos os conceitos trabalhados, e nos semestres mais avançados o papel integrador era dos estágios, em que os alunos fariam a aplicação prática dos conceitos desenvolvidos no decorrer do semestre".

Segundo os professores entrevistados, as disciplinas das unidades de aprendizagem integradoras foram concebidas para a realização de momentos de contextualização das unidades científicas, usando os pressupostos pedagógicos para o ensino de Ciências da Natureza. Nesses momentos, buscavam-se trabalhar de forma compartilhada as questões dos eixos temáticos que são vistos na educação básica, proporcionado aos futuros professores o desenvolvimento de habilidades que envolvam a realidade do aluno e a realidade da educação básica

Desde o início do curso estão previstas as práticas de ensino como componente curricular, "como forma de integrar 
conhecimentos e competências desenvolvidos à prática docente propriamente dita" (Lisboa et al., 2019). Nos quatro primeiros bimestres as práticas de ensino são desenvolvidas nas disciplinas integradoras através dos projetos integradores. Esse são momentos em que se faz a ponte entre os conhecimentos pedagógicos e os conhecimentos científico, do encontro entre as áreas da Pedagogia, Biologia e Química, onde são estudadas as formas de trabalhar em sala de aula conteúdos reais. Para o professor G, "são nesses encontros que os estudantes aprendem a mapear os conhecimentos prévios dos alunos sobre um determinado assunto, possibilitando a organização dos conteúdos que serão abordados, englobando diferentes áreas do conhecimento".

Nos quatros últimos semestres, as práticas de ensino como componente curricular ocorrem através dos quatro estágios supervisionados, momento para o desenvolvendo de suas competências, de modo a proporcionar ao aluno a construção do seu perfil de professor. Para os professores, esses são os momentos em que o supervisor de estágio auxilia o aluno na organização das aulas e realiza as visitas nos locais de estágio. Todo esse processo auxilia o aluno a formar sua identidade de professor, bem como a decidir se está no caminho escolhido.

Além disso, os professores preocuparam-se em organizar um currículo que formasse professores através de um enfoque interdisciplinar e significativo às realidades do Rio Grande do Sul, de Porto Alegre e da região metropolitana. Para isso, o curso possui uma maior conexão entre a Biologia e a Química, "uma vez que a Biologia e a Química na prática não são separadas, elas são interligadas, quem separa as disciplinas em caixinhas são os professores" (professor E). Bem como para o professor G:

A estrutura do curso estava alicerçada na perspectiva de que a ciências é interdisciplinar, e faz parte de um contexto maior, desse modo não é possível pensar só na Química, ou só na biologia. Ao trabalhar um conteúdo é preciso pensar em que contexto esse conteúdo está inserido, as questões químicas, matemáticas, sociológicas, entre outras).

Diante dessas constatações, os professores organizaram uma proposta de currículo integrado balizados pelas temáticas escolhidas para cada semestre, de modo que promovesse o diálogo entre as diferentes áreas envolvidas, qualificando o professor para trabalhar de forma interdisciplinar na educação básica. Fazenda (2011) afirma que são necessárias modificações não apenas na estrutura curricular, deixando de ser linear e passando a assumir um novo formato, mas é preciso também que as barreiras entre as disciplinas sejam eliminadas, permitindo assim uma interação disciplinar. A proposta do curso era de formar professores com cunho interdisciplinar, permitindo o desenvolvimento de conhecimentos mais amplos e interdisciplinar, de modo a preparar os alunos para fazer a leitura da realidade na qual está inserido.

\section{Superando os obstáculos e escrevendo um novo capítulo na educação}

O curso proposto pelos professores possui uma identidade única, com enfoque interdisciplinar e voltado para a formação de professores para atuarem na educação básica. A estrutura do curso valorizava as questões pedagógica, permitindo aos egressos um preparo tanto científico quanto pedagógico. Para o professor B, "a principal diferença do curso, essa formação pedagógica, a identidade dos alunos como professores, isso é disparado, sair com uma reflexão na área da educação muito diferente".

Para que o curso tivesse essa identidade pedagógica, foi preciso distribuir de maneira igualitária a carga horária das disciplinas pedagógicas e científicas, o que provocou algum desconforto na equipe docente. Alguns professores defendiam uma carga horária grande para as áreas pedagógicas, enquanto outros defendiam uma carga horária grande para científicas específicas da área de formação. Tais situações são comuns na construção de um curso, e a mesma pode ser evitada quando a estrutura curricular foi elaborada por um grupo de professores (Fazenda, 2017), tal como foi realizado na construção do curso em estudo.

Os professores das áreas específicas científicas tinham receio que os egressos não soubessem o suficiente das duas 
áreas, enquanto os das áreas pedagógicas frisavam a importância do enfoque pedagógico na formação dos professores. Apesar de tais receios, os professores acreditavam que estavam formando bons educadores e que a formação interdisciplinar permitiria aos egressos os subsídios para buscarem o aprofundamento dos conteúdos quando fosse necessário, além de fazer uma boa integração entre as duas áreas, assim como defende o professor $\mathrm{H}$ :

Os egressos não possuem um conhecimento aprofundado de Biologia e de Química, tal como se eles tivessem cursado uma faculdade de Química ou de Biologia somente, mas, apesar disso, esses egressos conseguem fazer uma boa integração entre essas duas áreas do conhecimento, além de existia a certeza de que seriam bons educadores.

A estrutura curricular interdisciplinar do curso apresentou, no decorrer dos semestres, alguns percalços nas disciplinas compartilhadas, em que professores de diferentes áreas dividiam a carga horária e os conteúdos. Alguns professores relataram constrangimentos de origem prática, tais como sobreposições de conteúdos e lacunas em outros conteúdos, além da dificuldade na avaliação dos alunos, em que a reprovação em uma das áreas e na outra não, ocasionando a reprovação na disciplina inteira.

Os professores também sentiam dificuldades na integração entre os conteúdos, e a promoção do diálogo entre as diferentes áreas nas disciplinas compartilhadas. Com isso, segundo o professor $\mathrm{C}$, na prática, "a disciplina acabava ficando modular, ou seja, os conteúdos eram divididos pelos professores conforme sua área de formação, ocasionando uma fragmentação da disciplina”. Tais fragmentações eram percebidas pelos alunos, que reconheciam as limitações de alguns professores, muitas vezes ocasionadas pela formação disciplinar e, segundo o professor B os próprios professores apresentam dificuldades de perceber a relação entre as áreas, pois possuem formações fragmentadas e mais específicas na sua área de formação. Por possuírem tal limitação, algumas vezes, o professor acaba passando para o aluno a responsabilidade em fazer a integração dos conceitos trabalhados nas diferentes áreas.

No início do curso aconteceram alguns desconfortos quanto ao formato das aulas de alguns professores das disciplinas científicas. Como o curso possuía uma característica inovadora e interdisciplinar, os alunos esperavam que todos os professores trabalhassem de forma inovadora, com diferentes estratégias de ensino e aprendizagem. Os alunos então questionaram o formato das aulas de alguns professores, que eram mais tradicionais, principalmente por possuírem uma formação mais tradicional. Esses questionamentos foram resolvidos quando esses alunos chegaram aos estágios, e então perceberam que em alguns momentos é interessante ter uma aula tradicional também, resolvendo dessa forma os desconfortos iniciais.

Alguns professores encontraram alguns gargalos nas disciplinas integradoras. $\mathrm{O}$ professor $\mathrm{C}$ relata que existiam dificuldades para trabalhar a importância de determinado conteúdo para a educação básica nas disciplinas científicas, e ao chegar nas disciplinas integradoras não conseguiam trabalhar o que haviam visto na disciplina científica pois era preciso trabalhar outros tópicos, como a didática e a contextualização. O professor $\mathrm{H}$ comenta que uma das dificuldades observadas no decorrer do curso foi a participação dos professores nos projetos integradores, devido à demanda de cada um, muitas vezes não era possível a participação de todos.

Além da estrutura curricular apresentar alguns problemas, como o fato de o curso ser de admissão anual, ocasionando muitas vezes a retenção ou até mesmo a evasão dos alunos. Quando alguns eram reprovados, eles acabavam ficando retidos por muito tempo, pois demorava um ano para aquele componente ser ofertado novamente, com isso alguns estudantes desistiam do curso.

Outra dificuldade estava relacionada à carga horária muito extensa do curso, além de disciplinas consideradas muito difíceis pelos discentes, que por vezes ocasionava reprovação. Tais reprovações ocorriam, muitas vezes, devido ao perfil do aluno que ingressa no curso, que são de alunos que trabalham, tendo menos tempo para se dedicar ao curso. Manter esses alunos no curso tornou-se um desafio, principalmente no momento atual, em que aumentam os cortes orçamentários na área da 
assistência estudantil (Lisboa et al., 2019).

Além da evasão por conta da estrutura curricular do curso e do perfil do aluno ingressante, existe também a evasão devido à desmotivação com a profissão professor. Segundo o professor E, "existe uma evasão de $50 \%$ de alunos no decorrer do curso, muito mais pela questão financeira [do profissional egresso] do que a questão filosófica, tendo como resultado um número pequeno de egressos". Alguns autores (Gatti \& Barreto, 2009; Moura \& Silva, 2007) realizaram pesquisas acerca da desvalorização da carreira acadêmica, relatando a pouca atratividade da mesma, principalmente na educação básica, seja pelas condições de trabalho ou pela baixa remuneração.

Diante dos obstáculos e percalços pelos quais o curso estava passando, em 2015 o mesmo sofreu uma reestruturação. Buscou-se acompanhar as novas diretrizes para formação de professores (Brasil, 2015), bem como, modificar algumas questões estruturais do curso. Segundo os professores, foi identificado que havia componentes muito grandes, carência de alguns conhecimentos, e sobreposição de outros. Com isso foi realizada um redimensionando dos componentes curriculares.

As disciplinas compartilhadas foram oficialmente divididas, tendo então redução de carga horária. A divisão da disciplina foi um importante passo para a resolução da fragmentação da disciplina pelos professores que a dividiam, pois, tal condição estava em descompasso com os preceitos de uma educação interdisciplinar, uma vez que trabalhar de forma interdisciplinar é superar a fragmentação dos conteúdos (Fazenda, 2011). Apesar de atender a uma das reinvindicações do corpo discente, a divisão das disciplinas compartilhadas ocasionou alguns desconfortos, devido à redução da carga horária. Segundo o professor B, "a carga horária que lhe foi retirada está fazendo falta para conseguir fazer um trabalho mais tranquilo, mas salienta que compreende que tal redução possa estar trazendo benefícios para os alunos no aprofundamento de uma outra disciplina".

As disciplinas das áreas científicas específicas também sofreram alterações, foi aumentado a carga horária das referidas disciplinas, visando resolver alguns impasses relativos à formação dos alunos. Ainda, alguns professores tinham receio quanto a dupla habilitação dos egressos, pois não seria possível encaixar em nenhum dos conselhos, Química ou Biologia, o que não foi um impedimento para o curso existir.

Apesar dos percalços que o curso enfrentou, a estrutura do curso permitia a formação de egressos com uma bagagem robusta quanto à formação pedagógica e científica. A dupla formação permitia ao professor transitar sem receio entre as duas áreas, fazendo associações e integrando conhecimentos. O professor $\mathrm{F}$ expõe o sucesso quanto à colocação dos egressos em escolas, "principalmente por estarem muito bem instrumentalizados, por serem efetivamente professores, possuem a experiência pedagógica".

Ademais, os egressos possuem uma bagagem das teorias educacionais que permite aos mesmos uma visão mais ampla sobre o campo de trabalho, do ponto de vista da atuação, sobre a visão da escola, sobre o processo de conhecimento dos alunos. Os que seguiram para os cursos de pós-graduação estão conseguindo aprovações nos processos seletivos devido ao fato do ser robusto quanto a formação humana e pedagógica, além de conteudista. Para os professores, o curso tem permitido a formação de egressos atentos as questões que perpassam o ensino, muito além das questões da prática docente, mas também as questões políticas que permeiam os espaços da educação básica.

\section{Conclusão}

A necessidade de formação de profissionais para a educação é um assunto recorrente nas pesquisas educacionais bem como pauta das Políticas Públicas. Se discute ainda, a importância da reestrutura do currículo dos cursos de Licenciatura, direcionado para o desenvolvimento da competência para além do domínio de conteúdo, mas voltados para a habilidade de articulação interdisciplinar. Conceber um curso de Licenciatura novo, construir e executar um currículo totalmente engajado com as tendências mais atuais da formação de professores não é uma tarefa fácil. 
O curso de Licenciatura de Ciências da Natureza: Biologia e Química, nasceu do entusiasmo de um grupo de professores que fazia parte da "antiga" Escola Técnica da UFRGS, quando a mesma foi incorporada pelo Instituto Federal Campus POA, criado através de uma Política Pública de incentivo à formação profissional, visando a igualdade social. O Instituto Federal IFRS entende que a educação é um instrumento de transformação, capaz de modificar a condição social, e contribuir positivamente para a realidade de cada cidadão, tornando assim, os espaços dos IFs locais fecundos para a democratização do ensino. Com isso, esse grupo de professores entendeu que o momento, por conta do contexto, era propício para o desenvolvimento de um curso inovador, capaz de modificar a estrutura de formação de professores, até então utilizada pela grande maioria dos cursos de licenciaturas, nos quais a formação pedagógica era uma complementação dos cursos de bacharelado.

Por meio da análise das entrevistas dos professores organizadores do curso, sejam eles pertencentes à "antiga" escola técnica, quanto aos novos professores, admitidos em concursos posteriores à criação do Campus, foi possível conhecer a experiência de cada um deles na trajetória de planejamento, criação e atuação no curso propriamente dito. Com esse trabalho foi possível compreender o que impulsionou a estrutura do curso, a qual estava destinada a atender a um público-alvo específico, formar professores de Ciências da Natureza, para aturar na educação básica do estado do Rio Grande do Sul ou pelo país.

Ao escutar os professores foi possível compreender a importância de estruturar o curso visando à prática pedagógica desde seu início com momentos de integração através de Projetos Integradores, práticas de ensino ou estágios supervisionados. Assim como salienta Vega et al. (2019), "o encontro interdisciplinar tem início no diálogo e interação dos integrantes ao elaborar a proposta didático pedagógica". Os professores estavam imbuídos com a proposta de um curso interdisciplinar, que tinha como base a construção de eixos articuladores, proporcionando a integração das diferentes áreas do conhecimento.

Apesar dos percalços e obstáculos do curso, o curso tem formado egressos com uma formação pedagógica e científica robusta, uma vez que os mesmos estão atuando como professores de diferentes níveis de ensino e, também tem conseguido aprovação em cursos de pós-graduação voltados para as pesquisas na área de ensino. O curso de Licenciatura de Ciências da Natureza: Biologia e Química está cumprindo o seu papel frente às emergentes necessidades de modificação da estrutura dos cursos de formação de professores e sendo um marco importante na história do Instituto Federal de Ciência e Tecnologia do Rio Grande do Sul - Campus Porto Alegre. Entendemos também, que pesquisas sobre a formação de professores são relevantes no meio científico e educacional, uma vez que uma educação de qualidade necessita de professores com formação superior e com habilitação específica na área a qual leciona. Desse modo, questões acerca dessas condições apresentam-se como um tema profícuo para pesquisa.

\section{Referências}

Brasil (1996). Lei 9.394 de 20 de dezembro de 1996. Estabelece as diretrizes e bases da educação nacional. Diário Oficial [da] República Federativa do Brasil. http://portal.mec.gov.br/arquivos/pdf/ldb.pdf

Brasil (1998). Secretaria da Educação Fundamental. Ciências da Natureza. Parâmetros Curriculares Nacionais - Ensino Fundamental. MEC/SEF.

Brasil (2000). Secretaria da Educação Média e Tecnológica. Bases Legais: Parâmetros Curriculares Nacionais - Ensino Médio, MEC/SEMTEC.

Brasil (2001a). Plano Nacional de Educação. UNESCO. http://unesdoc.unesco.org/images/0013/001324/132452porb.pdf

Brasil (2001b). MEC. Plano Nacional de Educação. Ministério da Educação. http://unesdoc.unesco.org/images/0013/001324/132452porb.pdf

Brasil (2002). Secretaria da Educação Média e Tecnológica. Ciências da Natureza, Matemática e suas Tecnologias. Parâmetros Curriculares Nacionais do Ensino Médio: Orientações Educacionais complementares aos parâmetros Curriculares Nacionais. MEC/SEMTEC.

Brasil (2006). Secretaria da Educação Básica. Ciências da Natureza, Matemática e suas Tecnologias. Parâmetros Curriculares Nacionais - Ensino Médio: Orientações Curriculares para o Ensino Médio (vol. 2). MEC/SEMTEC. 
Brasil (2008). Lei n ${ }^{\circ} 11.892$ de 29 de dezembro de 2008. Institui a Rede Federal de Educação Profissional, Científica e Tecnológica, cria os Institutos Federais de Educação, Ciência e Tecnologia, e dá outras providências. Diário Oficial [da] República Federativa do Brasil. http://www.planalto.gov.br/ccivil_03/_ato2007-2010/2008/lei/111892.htm

Brasil (2010). Plano Nacional de Educação. Ministério da Educação. fne.mec.gov.br/images/pdf/notas_tecnicas_pne_2011_2020.pdf

Brasil (2015). Resolução CNE/CP n ${ }^{\circ}$, de $1^{\text {o }}$ de julho de 2015. Define as Diretrizes Curriculares Nacionais para a formação inicial em nível superior (cursos de licenciatura, cursos de formação pedagógica para graduados e cursos de segunda licenciatura) e para a formação continuada. http://portal.mec.gov.br/pet/323-secretarias-112877938/orgaos-vinculados-82187207/12861-formacao-superior-para-a-docencia-na-educacao-basica

Brasil (2018). Base Nacional Comum Curricular (BNCC) (600p.). http://basenacionalcomum.mec.gov.br/images/BNCC_EI_EF_110518_versaofinal_site.pdf

Brasil (2019). Resolução CNE/CP N ${ }^{\circ}$ 2, de 20 de dezembro de 2019. Define as Diretrizes Curriculares Nacionais para a Formação Inicial de Professores para a Educação Básica e institui a Base Nacional Comum para a Formação Inicial de Professores da Educação Básica (BNC-Formação). http://portal.mec.gov.br/docman/dezembro-2019-pdf/135951-rcp002-19/file

Fazenda, I. C. A. (2003) Interdisciplinaridade: qual o sentido? Paulus.

Fazenda, I. C. A. (2011) Integração e interdisciplinaridade no ensino brasileiro: efetividade ou ideologia (6a ed.). Loyola.

Fazenda, I. C. A. (2017) Interdisciplinaridade: história, teoria e pesquisa (2a ed., 144p.) Papirus.

Gatti, B. A. (2014). Formação inicial de professores para a educação básica: pesquisas e políticas educacionais. Estudos em Avaliação Educacional 25(57), 2454. http://www.fcc.org.br/pesquisa/publicacoes/eae/arquivos /1899/1899.pdf

Gatti, B. A. \& Barreto, E. S. S. (2009). Professores do Brasil: impasses e desafios. UNESCO.

Gil, A. C. (1999). Métodos e Técnicas de Pesquisa Social (5a ed). Atlas.

Gil, A. C. (2014) Método de Pesquisa Social. Editora Atlas.

Japiassu, H. (1976). Interdisciplinaridade e patologia do saber. Imago.

Lisboa, C. P., Nichele, A. G., Zucolotto, A. M., Ortiz, H. S., Tallini, K., Prestes, L. M. \& Vieira, L. O. C. (2019). A formação docente no Curso de Licenciatura em Ciências da Natureza: Biologia e Química do IFRS - Campus Porto Alegre: desafios e perspectivas no contexto atual. ScientiaTec: Revista de Educação, Ciência e Tecnologia do IFRS. 6(2), 53-66.

Moraes, R. \& Galiazzi, M. C. (2011). Análise Textual Discursiva (2a ed.). Editora UNIJUÍ.

Moura, D. H. \& Silva, M. S. (2007) A evasão no curso de licenciatura em geografia oferecido pelo CEFET-RN. Revista Holos, 23(3) 26-42. http://www2.ifrn.edu.br/ojs/index.php/HOLOS/article/view/126/114

Nóvoa, A. (1995). Os Professores e sua formação (2a ed.). Publicações Dom Quixote.

Passos, C. G. \& Santos, F. M. T. (2010) A Resolução de Problemas na Formação de Professores de Química Brasileiros: análise da produção. XV Encontro Nacional de Ensino de Química (XV ENEQ), http://www.sbq.org.br/eneq/xv/resumos/R0352-1.pdf

Pierson, A. H. C. \& Neves, M. R. (2001) Interdisciplinaridade na formação de professores de ciências: conhecendo obstáculos. Revista Brasileira de Pesquisa em Educação em Ciências, 1(2), 120-131. L

Sacristán, J.G. (1999). Poderes instáveis em educação. Artmed.

Santomé, J. T. (1998). Globalização e Interdisciplinaridade: o currículo integrado. Artes Médicas.

Vega, A. P.V, Ribeiro, B. C., Padova, L. C \& Ghisleni, T. S. (2020). Interdisciplinaridade na produção de conteúdos educacionais: a relação teoria e prática. Research, Society and Development, 9(1). https://rsdjournal.org/index.php/rsd/article/view/1791/1556 